\title{
«Inventará la vértebra gramatical»: sobre Yo ya no vivo aquí de Cristina Rivera Garza
}

\section{1 (el momento es tan poco momento que casi parace una eternidad)}

Un momento casi inexistente, prácticamente invisible, define para nosotros la poesía de Cristina Rivera Garza: «(el momento es tan poco momento que casi parace una eternidad)», ${ }^{1}$ «(acaba de suceder un momento tan corto como la misma invisibilidad)». ${ }^{2}$ Este necesita la amarra del paréntesis para poder aprehenderlo, representa a la vez el todo y la nada, pues es sólo perceptible para algunos, mueve un resorte que a otros deja impávidos. Estos versos de «el lecho iridiscente», ${ }^{3}$ poema XVI de ¿Ha estado usted alguna vez en el Mar de Norte?, son una pista que nos guía a través «del bosque» (metáfora recurrente en la obra de la autora), que es la poesía (la obra) de la escritora mexicana, atravesada de intertextualidades, autorreferencial, plagada de imágenes que son universales, perpetuo ejercicio de rescritura, donde el yo se interroga sobre el lenguaje y sus posibilidades; al tiempo que sobre sus límites, hace del texto en el que se inscribe, rescribe, escribe, un ejercicio de lectura propia y ajena y nos lo «da a leer» (en sentido derridiano), fomentando una «comunidad lectora», invocando a la «multitud». ${ }^{4}$

Los autores de «La ficción más grande. La poesía de Cristina Rivera Garza» trazan magistralmente un mapa que nos guía por sus diferentes libros hasta Viriditas (2012) y explican cómo «Por cuestiones que tienen que ver más con aspectos canónicos y de mercado editorial la poesía de Cristina Rivera Garza ha permanecido a la sombra de su narrativa». ${ }^{5} \mathrm{Si}$ Los textos del yo es el poemario que ha

1 Cristina Rivera Garza: ¿Ha estado alguna vez en el mar del norte? Los textos del yo. México: Fondo de Cultura Económica 2005, p. 182.

2 Ibid., p. 184.

3 Mantenemos la minúscula en el título de los poemas de la autora.

4 Ignacio M. Sánchez Prado: «El fin de la memoria: 〈Tercer Mundo〉 de Cristina Rivera Garza». In: Oswaldo Estrada (ed.): Cristina Rivera Garza. Ningún crítico cuenta eso. . . México: Eón 2010.

5 Alejandro Palma Castro, Nathalie Galland Boudon et al.: «La ficción más grande: la poesía de Cristina Rivera Garza». In: Alejandro Palma Castro et al. (coord.): Cristina Rivera Garza: una

Beatriz Ferrús Antón, Universitat Autònoma de Barcelona

ə Open Access. (c) 2021 Beatriz Ferrús Antón, published by De Gruyter. (c) BY-NC-ND This work is licensed under the Creative Commons Attribution-NonCommercial-NoDerivatives 4.0 International License. 
recibido una mayor atención crítica, junto con el juego poético-narrativo de $L a$ muerte me $d a$, entendemos que todavía son numerosos los aspectos que quedan por ahondar en la obra de una escritora que es un insistente desafío y cuya escritura poética está todavía muy poco explorada. Nuestra lectura se centrará en Yo ya no vivo aquí, que junto a La más mía y ¿Ha estado alguna vez en el Mar del Norte?, configuran Los textos del yo (2005):

Los textos del Yo publicado por el Fondo de Cultura Económica en la destacada colección Letras Mexicanas se estructura a la manera de tres libros. El primero, que se corresponde a una reedición con ligeras variantes de La más mía, el segundo Yo ya no vivo aquí (2003) y el tercero ¿Ha estado usted alguna vez en el mar del Norte? (s.f). Pareciera que se plantea como un tríptico desde donde problematizar al signo del lenguaje y su poder a través del texto. A partir de un Yo se aleja con profunda rebeldía y busca un sentido no sujeto a su poder simbólico. Por ello, sus pulsiones van sobre la intuición de las palabras, el presentimiento del sentido y el tanteo de distintos textos desde un vientre figurado, resguardado del poder del lenguaje simbólico, para comunicarse con otro. ${ }^{6}$

Si hemos decidido comenzar con la cita de «el lecho iridiscente», ajena al libro en el que vamos a centrar nuestra atención, es porque el poema al que pertenece está plagado de claves para entender la poética global de la escritora mexicana. ${ }^{7}$ Este se subtitula «(el pronombre, el texto, la primera despedida)» ${ }^{8}$ y apunta a tres elementos decisivos: el lenguaje («pronombre») como categoría humana compartida que hace posible la comunicación, la experiencia individual y colectiva; «el texto» como discurso cultural que acumula capas históricas de sentido y que nos performa, pero que no existe sin el lector que lo alimenta; y «la primera despedida» como el momento de revelación del yo/cuerpo, que descubre que no existe sin el texto, fuera del pronombre, que el lenguaje es su gran riqueza, al mismo tiempo que su limite:

escritura impropia. Un estudio de su obra literaria (1991-2014). Puebla/México: Benemérita Universidad Autónoma de Puebla/Ediciones E y C 2015, p. 123.

6 Alejandro Palma Castro et al.: «La ficción», p. 130.

7 Muchos de los símbolos (el oyamel, el volcán, el bosque, etc.) que aparecen en el poema son comunes, por ejemplo, a varios de los relatos de la autora que hemos estudiado en otro lugar (Beatriz Ferrús: «Sirenas, salvajes y mitologías de género en la narrativa de Cristina Rivera Garza». In: Helena Usandizaga y Beatriz Ferrús (eds.): Fragmentos de un nuevo pasado. Inventario de mitos prehispánicos en la literatura hispanoamericana actual. Bern: Peter Lang 2015); así como lo son las intertextualidades con cuentos populares. Palma et al. identifican también este poema como significativo en el conjunto de Los textos del yo (Alejandro Palma et al.: «La ficción», p. 144).

8 ¿Ha estado usted alguna vez en el mar del Norte?: Cristina Rivera Garza: Los textos del yo, p. 182. 


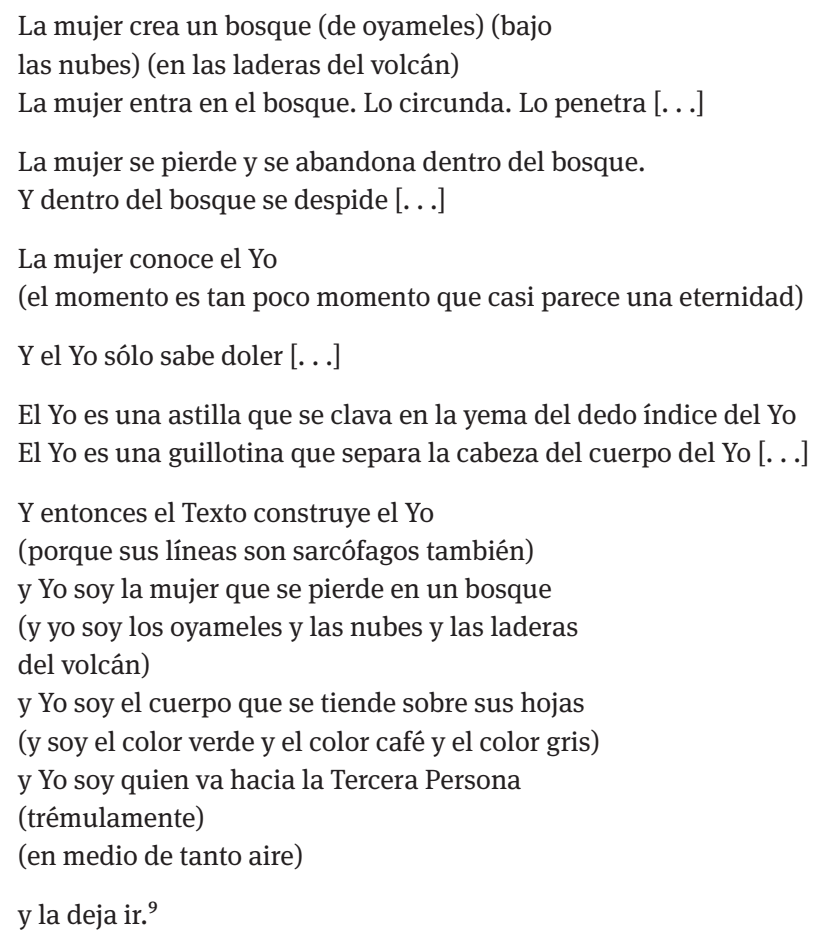

La mujer, una y a la vez múltiple, crea un bosque en el instante en que decide transitarlo, circundarlo, penetrarlo, porque el bosque, como el lenguaje, la literatura o la propia cultura, está plagado de misterios y recovecos, que existen en tanto son mirados, leídos, descubiertos, y es dentro de ese bosque donde $L a$ se convierte en yo, se encuentra con el espejo del Texto que la modeliza, del que toma conciencia y del que no puede salir, pues sin lenguaje no hay sujeto, sin cultura no hay mujer (la crea a su vez). «Y el yo solo sabe doler», porque el deber ser lo atraviesa, porque se sabe atrapado en la tercera persona, porque es consciente de la falacia de su existencia, de su inestabilidad; pero, asimismo, porque el Yo es una astilla que se clava, ya que es un cuerpo que duele. Lenguaje y cuerpo no existen uno sin el otro, son indisociables, se pelean, confunden sus límites. ${ }^{10}$

9 Ibid., p. 182-184.

10 Palma et al. proponen leer Los textos del Yo desde la idea de finisterre: «Horizonte de la escritura poética, este finisterre se despliega en torno al yo, foco de intimidad cambiante, doliente [.. .] la radicalidad de una escritura crítica [. . . Finisterre y horizonte, dos términos para decir una relación de escritura con el espacio (Alejandro Palma et al.: «La ficción», p. 131-132). 
De esta forma, la poesía «es tan poco momento que casi parece una eternidad». Se trata del instante en el que se descubre el imperio del lenguaje, la sumisión del sujeto a este, pero también la posibilidad de jugar con él, la «revolución» en potencia que contiene; ${ }^{11}$ así como el poder del cuerpo que lo/en el que se sustenta y sin el que sería imposible: «Rivera Garza otorga a la poesía una misión cultural que pocos discursos pueden asumir en los tiempos que corren: figura, aunque sea en los territorios del signo, esa revolución a la que al parecer muchos han renunciado». ${ }^{12}$ "El lecho iridiscente» alegoriza el lapso en que la luz solar que nos acompaña a diario se descompone en colores y se hace visible al ojo humano, de la misma forma que el lenguaje se revela casi como en una visión mística. ${ }^{13}$

Desde aquí, la «Exhortación primera: ¿quieres saber lo que se siente?» de Yo ya no vivo aquí constituye una variante del mismo mensaje: «Ávido lector: no se siente nada» «Ávido lector: sólo en la memoria (que es puro lenguaje) sentimos». ${ }^{14}$ Esta advertencia contiene ya varias de las marcas que se van a reiterar en el libro: repeticiones incesantes, oraciones principales que se acompañan de largas listas de subordinadas, uso reiterado de pronombres personales y de adverbios de lugar, que se llenan de experiencias individuales, pero que se saben de uso comunal, «la disolvencia del yo en la multiplicidad de la comunidad», ${ }^{15}$ etc., en tanto maniobras que persiguen un mismo fin: recordarnos que el lenguaje y la cultura habitan en sincronía y diacronía, son fruto de la experiencia vivida; al tiempo que de la historia. La metáfora siempre es dura y, a menudo, corporal. El lector es golpeado más que apelado.

Tras esta exhortación el libro se subdivide en cinco partes: «El lugar», «Maneras de entender el lugar», «Los personajes del lugar», «Los vacíos del lugar» y la «La tercera parada» y tiene dos grandes protagonistas: la voz poética y la «Ciudad Más grande del Mundo», como el escenario («El lugar») por el que transita. Las tres primeras partes acumulan el grueso del sentido y las dos últimas sirven de paréntesis y de colofón, sin que estas funciones sean menores, como se verá más adelante. El objetivo de este ensayo es recorrerlas, proponiendo una lectura del conjunto del libro que carece de cualquier afán de exhaustividad, sino que se plantea como un «cuerpo a cuerpo», como una conversación o un diálogo personal con el libro.

11 Julia Kristeva: La révolution du langage poétique. Paris: Editions du Seuil 1981.

12 Ignacio M. Sánchez Prado: «El fin», p. 288.

13 El disco de Newton. Ensayos sobre el color (2012) comparte una misma búsqueda, aunque esta explore otras posibilidades formales, la «filosofía poética» es común. La prueba del disco es el fenómeno inverso a la iriscencia, pero alegoriza una misma pregunta o instante de develación.

14 Cristina Rivera Garza: Yo ya no vivo, p. 88.

15 Ignacio M. Sánchez Prado: «El fin», p. 288. 


\section{Yo ya no vivo aquí}

\subsection{El lugar}

«El lugar», título que apunta al sitio, paraje, ciudad. . . donde una trama acontece, se inaugura con «que bueno que no están», poema montado sobre el adverbio aquí, categoría vacía en la que puede caber una época histórico-vital, que no es solo geográfica, sino vivencial, incluso sensorial. El recuerdo y el tiempo la han tamizado. La página escrita reubica el sentido del sitio y a sus descarnados personajes:

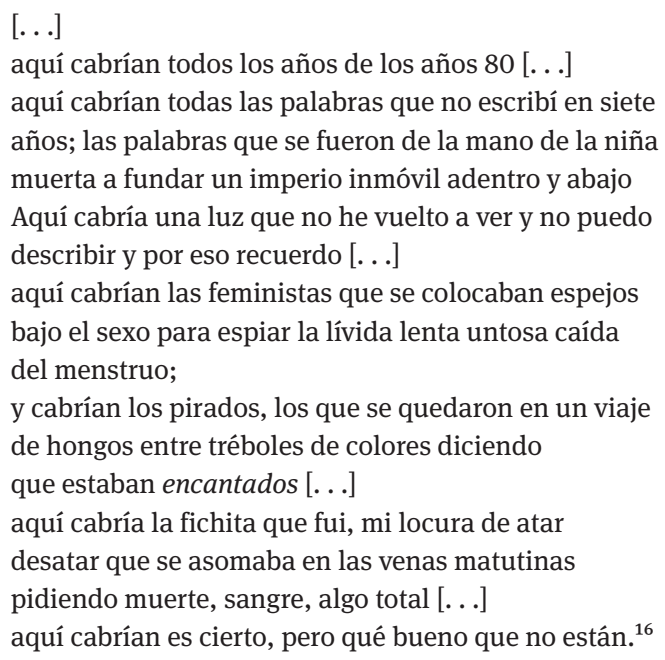

El Aquí escrito, poético, es el del recuerdo de una etapa de la que no se reniega, pero cuyas ausencias «qué bueno que no están» han permitido la escritura: «Aquí en este cuarto de perfectos muros blancos», ${ }^{17}$ han hecho posible «pasar página».

Las «notas finales» con las que se cierra el libro sitúan el comienzo de su redacción en 1997, con la llegada de la autora a San Diego, y la revisión final en 2003, tras su regreso a México con una beca:

Todos los libros son comunales se sabe. Pero este es el más comunal de mis libros. Se lo debo, sin metáfora alguna, a ciertas calles, algunos años y un puñado de personajes entrañables. Ellos y yo, y también otros, saben quiénes son. Este libro, que no es ni una confesión

16 Ibid., p. 89-92.

17 Ibid., p. 92. 
ni un recuento sino, en el más estricto de los sentidos, una imposibilidad, es naturalmente para ellos. Y ellos, por supuesto, es solo otra manera de decir nosotros. Los cómplices de lo real. Una forma del alfabeto. ${ }^{18}$

Si esta cita empuja a plantearse, al menos, la posibilidad de una lectura autobiográfica, la exhortación primera: «¿quieres saber lo que se siente?», nos desafía a una «comparecencia mutua»:

La lectura queda al descubierto aquí no como el consumo pasivo de un cliente o de un público (o pero aún: de una carencia de público, sino como una práctica productiva y relacional, es decir, como asunto de estar-con-otro que es la base de toda práctica de comunidad, mientras esta produce un nuevo texto, por más que parezca el mismo. ${ }^{19}$

La auto-bio-grafía es bios (vida/cuerpo), grafía (letra) y auto (reflexividad, subjetividad). El lector que se aventura en Yo ya no vivo aquí verá como estos tres componentes son desmontados y vueltos a montar en un puzzle imposible, pero fascinador, que lo deja perplejo. La lucidez metapoética nos acompaña en una suma de breves momentos que casi parecen una eternidad.

Los años ochenta del poema no se encuentran tan alejados en su descripción de la caracterización histórico-social de esta época en otras geografías de Occidente, bien podrían ser el escenario de las películas del cine español de la movida, pero la «fichita que fui» ¿en el juego de la vida? los personaliza e invita al lector a leer con ella, desde ella. La poesía se hace memoria, singular, descarnada, pero humana, demasiado humana y, por tanto, colectiva. El aquí deviene un universal, a la vez que es temporal y es local. Resulta invocado desde la escritura, aunque solo existe por esta y en ella. Este podría ser muchos lugares a la vez; no obstante, si el lector tiene la tentación de olvidarse de uno concreto: México - ¿Son los «humanos restos, los difuntos fieles» los que llevarán a «dolerse por un país herido»? - El Terzo y la Ciudad Más Grande del Mundo lo evocan en «tercer mundo».

«Estaba en una orilla de la orilla», ${ }^{20}$ la periferia de la periferia se asemeja a la recreación posmoderna de los cuadros del Bosco. La primera persona se desliza en el segundo de los poema hacia un nosotros, que emerge encarnado en las últimas estrofas tras transitar por un los/las: «y fui el hombre y fui la mujer / mi concavidad fue el estado de sitio de las/metamorfosis». ${ }^{21}$ El borrado de la marca

18 Ibid., p. 142.

19 Cristina Rivera Garza: Escribir no es soledad. México: Universidad Autónoma de México 2014, p. 30.

20 Ibid., p. 93.

21 Cristina Rivera Garza: Yo ya no vivo, p. 100. 
de género nos recuerda que hay sociedades donde importa más pertenecer a «El Terzo» que ser hombre o mujer: ${ }^{22}$

[...]

¿Cómo volver a decir El Terzo sin apagar ese cerillo

de palabras

esa inaugural iluminación que desvela

al dactilar verídicamente?

Éramos un asomamiento vertiginoso tras las venas

una laboriosidad aérea de piernas y uñas y cartílagos.

Éramos saliva $[\ldots]^{23}$

La metáfora se vuelve hiperbólicamente corporal. La escritura se hace carne, órganos y excrecencias la pueblan. ${ }^{24}$ Los sentidos se tensionan al máximo y la sonoridad del poema los acompaña.

Ignacio M. Sánchez Prado en «El fin de la memoria: 〈Tercer mundo〉 de Cristina Rivera Garza» lee de manera magnífica esta composición, subrayando su falta de antecedentes en la historia de la poesía mexicana:

«Tercer Mundo» es un poema narrativo y distópico, que, en cinco movimientos, narra la invasión de la ciudad de México por parte de los habitantes de sus cinturones de miseria [. . . L La elección de un término con una carga simbólica tan amplia y con un cierto grado de anacronismo otorga al poema un cierto aire irónico, fundado en una significación paradójica: por un lado, el término «Tercer Mundo» describe el espacio desde la perspectiva de los privilegiados, enfatizando el sentido de resto o excedente que el término tenía en su acepción original. Por otro, al introducir cierta duda en el uso del término a partir de su derivativo «El Terzo» el poema establece la posibilidad de deconstruir la dimensión marginal de dicho espacio, y, eventualmente, adoptar la perspectiva de los marginados. ${ }^{25}$

El crítico señala la originalidad de la convivencia de tres elementos raramente presentes en autores anteriores: un tema político y utópico, un sujeto colectivo

22 Aunque entendemos que se apunta aquí una reflexión sobre el género que podríamos llamar «poscolonial», no es el único sentido posible, sino que esta interpretación se puede llevar más allá, a la total revisión, incluso a la impugnación, de la misma categoría de género. Sobre la compleja reflexión en torno al género en Rivera Garza, véase Estrada, quien explica «podemos apartarnos momentáneamente de los rótulos genéricos, binarios, maniqueos, reduccionistas con los que a las puertas de un nuevo milenio siguen construyéndose las identidades personales, comunitarias, nacionales o globales» (Oswaldo Estrada: «Cristina Rivera Garza, en-clave de transgresión». In: Oswaldo Estrada (ed.): Cristina Rivera Garza. Ningún crítico cuenta esto. . . México: Eón 2010, p. 197).

23 Cristina Rivera Garza: Yo ya no vivo, p. 100.

24 Sobre la importancia del cuerpo en la obra de Rivera Garza véase Cecile Quintana: «El cuerpoescritura de Cristina Rivera Garza». In: Graffylia 17-18 (2013), p. 130-142.

25 Ignacio M. Sánchez Prado: «El fin», p. 280. 
y el protagonismo de una ciudad muy sórdida. ${ }^{26}$ Con distintas variantes, los tres son explorados hasta la saciedad en los poemas siguientes, aunque en esta composición alcanzan su sentido político más explícito.

\subsection{Maneras de entender el lugar}

Aquí vuelve a ser el protagonista en «la gramática del lugar» que inaugura la segunda parte, pero la metáfora corporal que con tanta fuerza emergía en la composición anterior, se torna, a partir de este instante, ineludible. El adverbio antes vivido y sentido, que brotaba en la página como lugar cargado de recuerdo, acontece puro lenguaje: «el candado de un vocabulario perpetuo»; pues cualquier afuera es una utopía: «no hay tal lugar», incluido el del cuerpo. Este se territorializa en el lenguaje, existe gracias a él y lo hace existir. El verbo se hace carne y la carne es verbo, en un ejercicio combinatorio indecidible e indisociable:

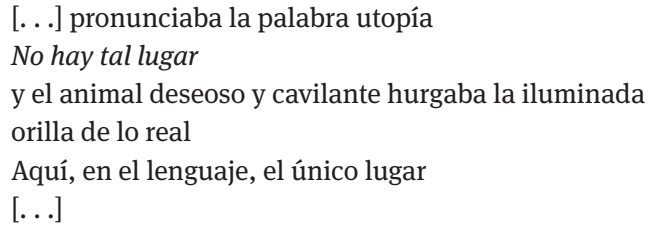

Aquí se repite y repite, ganando en intensidad; mientras demuestra la imposibilidad de un sentido unívoco. La «gramática», «Decía dame un cuerpo e inventaré

26 Ibid., p. 283-284.

27 Cristina Rivera Garza: Yo ya no vivo, p. 103-104. 
la vértebra gramatical», apunta al arte combinatorio: «conjugación», «plurinominal», «árboles nominativos». Magritte se cita, «(me señalo el ojo izquierdo y surge, de pronto, la nube / de Magritte sobre una llanura escarlata)», ${ }^{28}$ como referente pictórico de un mismo problema: los tenues y complicados vínculos entre palabra, imagen y objeto, que se rescriben como cuerpo-imagen(lenguaje poético)-lugar (geográfico y vivido). «La vértebra gramatical» remarca la indisociable y compleja relación entre cuerpo y lenguaje, entre experiencia y poesía: «una genética de tiempo vuelto gota y calle / y esquina enigmática», ${ }^{29}$ "aquí, subjuntivo deseo de lo que hubiera sido». ${ }^{30}$ Por eso, si en la «gramática del lugar», el «aquí» pueden llenarse de cualquier experiencia humana, asociada a una realidad geográfica, el poema no deja de anclar la suya «aquí Ciudad más Grande Del Mundo / aquí fractura de tierra». ${ }^{31}$ La elusión del nombre propio no sólo recuerda cómo la diacronía de un territorio siempre lleva aparejados muchos nombres, los de las violencias históricas de «la geología del lugar», siguiente de los poemas, sino que subraya el valor arquetípico y personal de la mirada hacia un espacio, la territorizalición de la vivencia afectiva, la modelización de los sujetos por los discursos históricos y sociales sobre una geografía. ¿Cómo ponemos el cuerpo en una ciudad? ¿Cómo nos afecta o desafecta? «la sintomatología del lugar» explorará esta idea. Todo espacio reúne capas infinitas de sentido. Por eso aquí no es solo un adverbio vacío, sino que está presto a llenarse hasta rebosar, constituye un permanente desafío para la palabra poética.

De esta manera, los dos poemas siguientes profundizan en los recorridos apuntados: «la geología del lugar» se pregunta por el antes, por el origen, por el momento inaugural, por el nacimiento de la ciudad: «antes de la destrucción y del púrpura polvo mortecino». ${ }^{32}$ ¿Existe el «afuera» del lenguaje y de la historia, aunque sea en el origen? Ese antes es «un bostezo largo y hundido», cuerpo presto a despertar; al tiempo que «el sonido persiguiéndose dentro de la garganta» se refiere al lenguaje que espera ser articulado. Cuando el cuerpo despierta, la palabra brota de la garganta y comienza la historia, con sus conquistas y violencias. La ciudad, como el cuerpo de una mujer, es dolor, a la vez que milagro de vida:

28 Ibid., p. 103.

29 Ibid., p. 104.

30 Ibid., p. 103.

31 Ibid., p. 104.

32 Ibid., p. 106. 


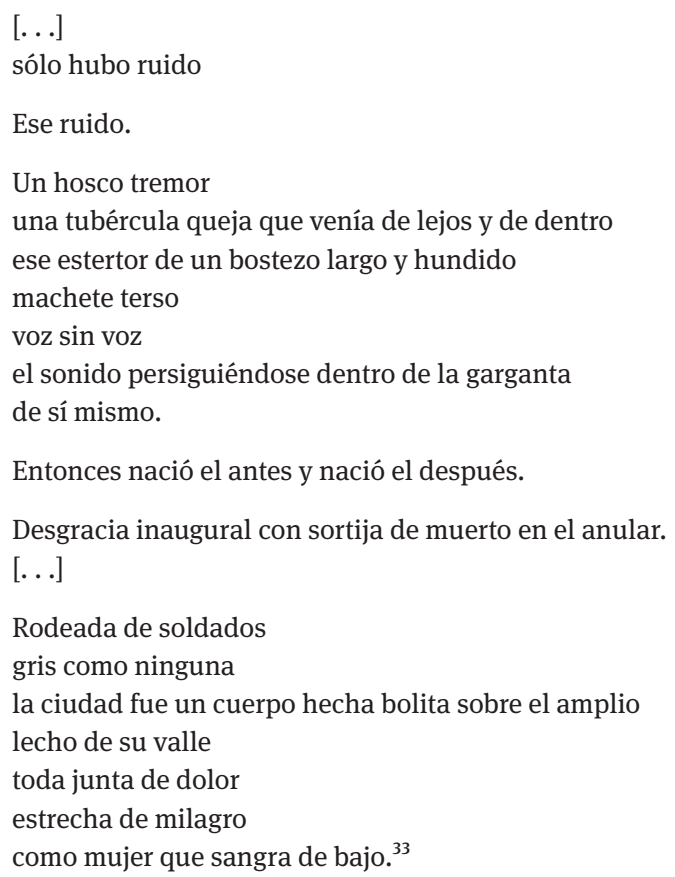

La historia de la urbe y del ser humano que la habita y la nombra oscila entre el «arriba y abajo del lugar». El arriba insinúa la dimensión divina, que refleja lo inaprehensible del conocimiento: «la primigenia nube original sobre la cual están basadas / todas las demás nubes de todos los universos / habidos y por haber». ${ }^{34}$ La nube evoca lo celeste, el misticismo - pensemos en La nube del no saber del siglo XIV-, pero esta no parece ser tomada demasiado en serio. Ha servido a Magritte y a otros motivos que nada tienen que ver con la explicación religiosa del mundo o las cosas: «La nube como modelo ideal. / Gris azul / Azul humo-nata / Violeta-rojo-morado-moretón. Negras como la gran señora de la guadaña». ${ }^{35}$

Del mismo modo «el abajo del lugar» es el de la dura experiencia de la cotidianidad contemporánea, ajena a cualquier eco de religiosidad: el Metro, pero cuyo cuadro algo tiene de infernal. La historia de las cosas, de los símbolos, de la cultura, está presta a cambiar de significado: 


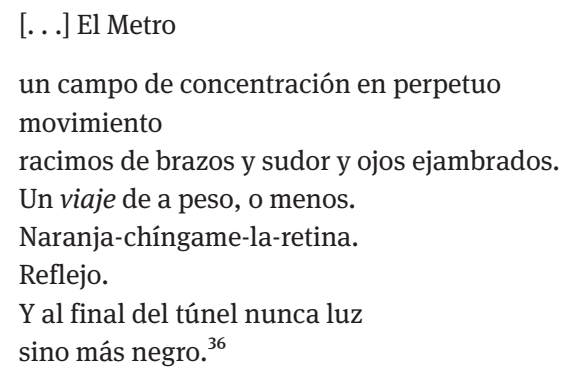

Por otro lado, «la sintomatología del lugar» se pregunta por la condición escindida del sujeto contemporáneo y recoge la pregunta sobre cómo ponemos el cuerpo en una ciudad (o dos). El poema se transforma en una enumeración de síntomas ocasionados por el perpetuo desplazamiento, por la escisión entre países, entre culturas. Esta es fruto de la globalización, de las migraciones profesionales, amorosas, por deseo o por necesidad, de «algunos» que acabamos perteneciendo a dos lados y a ninguno a la vez «Están aquí y no están aquí; ellos están allá y no aquí / y tampoco allá», ${ }^{37}$ de quienes hacemos malabares con nuestros cuerpos y nuestras geografías afectivas o necesarias «Bailan en la cabeza de un alfiler». ${ }^{38}$ Las enumeraciones son incesantes. Si habitar un territorio o «rebotar» de uno a otro implica poner el cuerpo de múltiples formas, el reto provoca efectos secundarios. Afecta a la estabilidad cultural, revela su dimensión geolocalizada, su condición de «relato»: «Algunos se vuelven religiosos, otros rechazan / categóricamente la existencia de dios». ${ }^{39}$ Los hábitos cotidianos se modifican: «algunos beben té de menta [. . .] algunos se mueren por papas fritas» $;^{40}$ causa soledades y nostalgias, encuentros y aprendizajes, abre siempre la mirada, descubre las falacias de toda «norma»: «Ellos conocen la gravedad de las cosas»: $:^{41}$

[.. .] Algunos sufren de dolores de estómago, falta de aire, Demasiados lenguajes, migrañas, ataques violentos de timidez, discriminación, asma, palpitaciones estereotipos, demasiados lenguajes, mal aliento, huesos nostalgia, acné, mala memoria, demasiados lenguajes [...]

36 Ibid., p. 104.

37 Ibid., p. 113.

38 Ibid., p. 113.

39 Ibid., p. 110.

40 Ibid., p. 111.

41 Ibid., p. 113. 


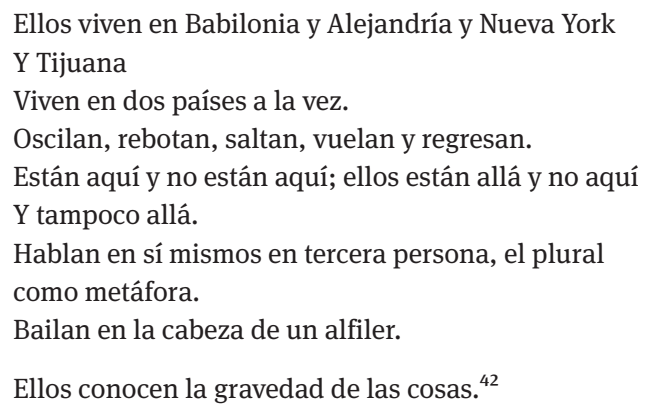

Como un paso más allá, «la anatomía del lugar» demuestra su poderosa inscripción física, gracias a la cual «existe sin ser», ${ }^{43}$ «se imagina a sí mismo y estalla en luces asimétricas». ${ }^{44} \mathrm{El}$ lugar se clava «bajo la uña», se instala «en la canícula del esófago», ${ }^{45}$ «el lugar trae su aguja y pincha y cose / la tapicería de los miembros». ${ }^{46}$ Las metáforas son incisivas, mordientes, atraviesan al lector sin dejar opción a la duda o a la huida, lo obligan a pensar en sus propias cicatrices, a participar, de nuevo, en la «comparecencia mutua» de la lectura: ${ }^{47}$

en el ácido ribonucleico de los días

el lugar graba el alfabeto de las cosas invisibles

(ganzúa en mano, pala y pico en dientes)

[...]

En el tendón que es campana

en el cartílago que iba a ser hueso

en la vertebral columna del adentro

el lugar existe sin ser

la carne como verbo. ${ }^{48}$

A este respecto, Palma et al., en el ya mencionado artículo, explican:

La carne, en estas circunstancias, se vuelve el foco donde se inscriben los movimientos y correspondencias del mundo y del lenguaje. Por lo tanto, no es una esfera inmóvil o clau-

42 Ibid., p. 113.

43 Ibid., p. 115.

44 Ibid., p. 114.

45 Ibid., p. 115.

46 Ibid., p. 114.

47 «Si la lectura, como lo he repetido tanto, no es un acto de consumo pasivo sino una práctica de comparecencia mutua, un minúsculo acto de producción colectiva» (Cristina Rivera Garza: Escribir, p. 45).

48 Cristina Rivera Garza: Yo ya no vivo, p. 115. 
surada. En la carne, se evidencia la huella de todos los recorridos seguidos en el espacio y el mundo del pensamiento, y también la invitación a emprender nuevos recorridos al encuentro del otro y del universo. Un llamado a la palabra. Una poesía de la encarnación a partir de la cual se interroga la conexión entre el cuerpo, el mundo, la palabra y el sentido. ${ }^{49}$

¿Cómo podría si no el lugar generar síntomas? Este es experiencia, «conexión entre el cuerpo, el mundo, la palabra y el sentido»; así como «discurso», sustratos de historia y de cultura que performan los cuerpos y guían los sentidos, que se descubren en este proceso de búsqueda, como hemos ido viendo. «las muchas mentiras del lugar» abunda en este aspecto y completa la pesquisa añadiendo nuevos matices.

Por eso el lugar es «alegoría, metáfora, ardiente comparación», «argumento, hipótesis, inmoral objeto de estudio»..$^{50}$ Este es narrado «En los pocos entrañables libros había párrafos / que lo traían como enigma, vocación, estilo» ${ }^{51}$ y vuelto a contar por una voz poética consciente del poder de los imaginarios, de sus «mentiras». Las reminiscencias a los cuentos populares así lo subrayan:

\section{$[\ldots]$}

érase que se era

y el hombre vuelto mujer se adiestraba en los tres filos

de la leyenda, los once picos de la maravilla

habíase una vez

un lugar hermoso porque era mío. ${ }^{52}$

El último de los versos de la segunda parte del poema: «Un lugar hermoso porque era mío» convierte al posesivo singular «mío» en el signo de lo dialógico, en el que escritura y lectura se reúnen en un bucle eterno. Ese «mío» ya no es solo del sujeto poético, sino de todos los que la hemos acompañado y de aquellos que la acompañarán.

\subsection{Los personajes del lugar}

En el primero de los poemas de la tercera parte, «los personajes del lugar» son descarnados, pero susceptibles de generar ternura. El yo se encuentra aquí con la alteridad, la penetra o se deja atravesar por ella y asume las cicatrices que esta

49 Alejandro Palma et al.: «La ficción», p. 136.

50 Cristina Rivera Garza: Yo ya no vivo, p. 116.

51 Ibid., p. 117.

52 Ibid., p. 118. 
deja a su paso. Sin el otro, el lugar sería un frío aquí, el sonido continuaría persiguiéndose en el interior de la garganta. «la palabra arisco» cualidad que evoca a los gatos callejeros, describe con dureza a su protagonista «Era tan feo que daba pena / daban ganas de no tener ojos» ${ }^{53}$ para después apiadarse de él:

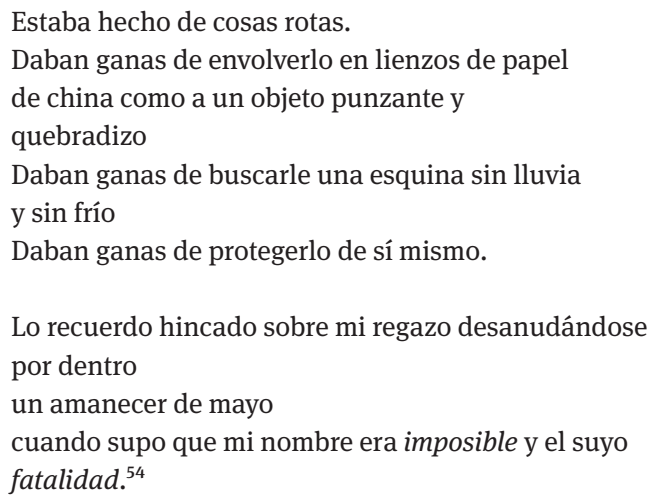

La ternura que suscita no es suficiente para salvarlo o salvarse con él, a través de él. El sustantivo fatalidad, en cursiva y colgando sobre el blanco final de la página, anula cualquier posibilidad de redención o final feliz.

Por otro lado, «la pura felicidad» se monta paradójicamente sobre el verbo «Dolía»: «Dolía como duelen a veces las cosas, de pura felicidad». ${ }^{55} \mathrm{El}$ amor vivido, pero perdido, ha dejado marcas eternas y ha hecho a la voz poética otra con el otro, por el otro: «Él me escribió seis cartas desde la orilla de un futuro / que casi alcanza a la orilla del pasado». ${ }^{56}$ Los tres puntos suspensivos, que dividen la composición, separan dolor de recuerdo, aunque este puede ser igualmente doliente. No obstante, es uno de los poemas más «hermosos» del libro. Se trata del «personaje del lugar» más querido:

Lo recuerdo cuando tomo té de menta y la noche se deshace en húmedos acertijos.

Lo recuerdo como algo que duele recordar dentro de un cuarto lleno de esquinas. ${ }^{57}$

53 Ibid., p. 119.

54 Ibid., p. 120.

55 Ibid., p. 122.

56 Ibid., p. 123.

57 Ibid., p. 123. 
Sin embargo, «el ángel aleccionador» y «lo que iba a escribir» dibujan dos relaciones tóxicas. El ángel aleccionador «quiere que», sintagma que, seguido de numerosas subordinadas, dibuja la pretensión de anular al sujeto del poema «Que sea nadie, menos que nadie»:

quieres darme una lección.

Quieres que aprenda a guardar el silencio bajo

la lengua mientras los ilusos hablan.

Que yo me vuelva como tú, eso quieres. Que sea

nadie, menos que nadie.

Una brizna de hiel en un frasco de formol [...]

Quieres ser un dios caído, una fruta agria, un ángel

aleccionador. ${ }^{58}$

Mientras «lo que iba a escribir» corrige la escritura de un «te quise» al recordar episodios de violencia física:

Tú me quebraste en dos como una vara

tú te detuviste a llorar junto a mi boca y mi sangre

te empapó las pestañas

tú eres la palabra moretón inscrita en mis enzimas

con letras pequeñas.

Letras de ácido ribonucleico y ácido

desoxirribonucleico.

Letras diminutas.

Iba decir te quise pero de repente se me quitaron

las ganas. ${ }^{59}$

Por último, la voz poética se enfrenta a sí misma y al espejo del tiempo en las últimas tres composiciones. En «la juez»: «Te llamabas días en que fui feliz», ${ }^{60} \mathrm{se}$ pregunta por la veracidad de la remembranza que la conmueve: « $¿$ Existieron las luces?». Mientras en «y wendy creció» $\mathrm{y}$ «divino tesoro», dos títulos que apuntan al personaje de Peter Pan y al dicho popular «juventud divino tesoro» -sin olvidar la intertextualidad con el poema de Darío del mismo título-se interpela a sí misma con dureza:

He dicho que no te perdono nada

Fichita azul, tipa de cuidado, bocaza de trementina.

Acércate para que me escuches mejor

58 Ibid., p. 124-125.

59 Ibid., p. 128-129.

60 Ibid., p. 131. 
esta es la sentencia:

y Wendy creció. ${ }^{61}$

La «fichita» del primero de los poemas del libro vuelve a aparecer. Ha concluido una etapa del juego de la vida a la que se confronta sin perdón, «no te perdono nada», pero, paradójicamente, con aceptación. La Wendy de Peter ha asumido su madurez y juzga severamente a la «tipa de cuidado»; pero los versos están impregnados de pasión, sin esa Wendy no sería quien es hoy. Por eso en «divino tesoro», aunque «Mi juventud no es una dama, nunca fue la edad más / hermosa como la de Nizán, una bugambilia», ${ }^{62}$ el momento de la despedida definitiva es «La hora de la crueldad más veloz»: ${ }^{63}$

\author{
Mi juventud me da lástima y me da rabia y ganas \\ de salir corriendo tras sus huellas de perro apaleado, \\ cojitranco y hambriento. \\ Íbamos a vivir toda la vida juntas, dijo. \\ Me extrañarás, aseveró. \\ Mi juventud siempre supo más que yo. ${ }^{64}$
}

\title{
2.4 Los vacíos del lugar
}

La cuarta y más breve de las partes del libro está dedicada al vacío, a la falta. La interpretación queda abierta a diversos sentidos:

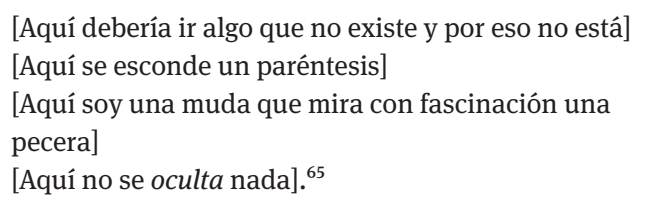

¿Son estos vacíos de lugar las fallas de la memoria, las carencias de toda historia personal, lo que queda fuera del ejercicio de la escritura o una pregunta por los límites del lenguaje?, ¿apuntan a las lecturas infinitas del texto literario por venir? ¿O son los huecos y silencios de un país concreto que años después Cris-

\footnotetext{
61 Ibid., p. 134.

62 Ibid., p. 136.

63 Ibid., p. 137.

64 Ibid., p. 137.

65 Ibid., p. 138.
} 
tina Rivera Garza tematizará en «Me llamo cuerpo que no está» (2015)? Son todos a la vez y muchos más.

\subsection{La tercera parada}

El título «tercera parada» remite a «tercer mundo», a «Terzo», y permite leer ambos poemas en continuidad. No obstante, es algo más, una apoteosis final, un apocalipsis distópico, que, como en el caso de «tercer mundo», subraya la potencialidad revolucionaria de quienes habitan el margen, promete una regeneración sobrevenida tras la destrucción; al tiempo que reúne muchas de las metáforas, de los personajes, que han ido recorriendo el libro para resignificarlos:

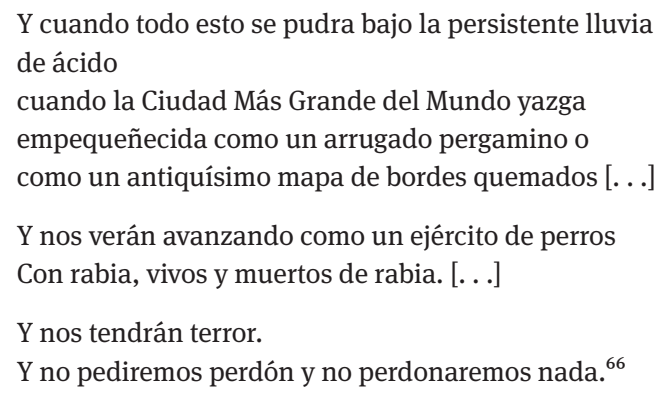

Aquí, «los orates, los locos de remate, las piratas», «los difuntos fieles», «las feministas» el efecto sumativo, desencajado y desplazado, de las intertextualidades del último de los textos con el conjunto del libro, no solo le otorga a la «tercera parada» una poderosa e inquietante intensidad acumulativa, sino que parece hacer del presente y, sobre todo, del futuro, el vaticinio de un estallido, de una revuelta inquietante e irremediable, cuyos efectos no son posibles de calibrar.

\section{Inventaré la vértebra gramatical}

Nos dirá Rivera Garza en «Saber demasiado» que

Atiendo a mi historia como lectora y atestiguo que los libros que me han marcado, esos a los que regreso una y otra vez con la curiosidad intacta, no son aquellos que me aclaran, ilustran o develan (todos verbos lumíferos, en efecto), la así llamada realidad, sino aque-

66 Ibid., p. 139-141. 
llos que me inquietan con su oscuridad, me problematizan con sus preguntas sesgadas o secretas, y me atenazan con sus desvaríos. [. . .] «Prefiero el libro, que pegado a la lengua, se disuelve para ser lo que es: cuerpo. Cosa viva». ${ }^{67}$

La lectura de un libro como Yo ya no vivo aquí nos produce ese mismo efecto: el de las preguntas secretas, que nos llevan a releer insistentemente los poemas con pasión, con misterio, pero también con incertidumbre y desasosiego; que nos crean efectos físicos, secundarios, que nos permiten pensar la poesía de otra manera, que nos llevan a tomar conciencia de esa «comparecencia» a la que se nos convoca. Visitar el «aquí» de Rivera Garza es participar de este sin acabar de saber del todo qué es lo que esto significa: «Leerla es traspasar los límites del lenguaje, cruzar las fronteras de diversos géneros y quedar al filo del suspenso con muchas preguntas y pocas respuestas». ${ }^{68}$

La búsqueda de la «vértebra gramatical» invoca al sostén de la poesía, a su eje. Los poemas no resbalan por nuestro cuerpo, sino que se clavan como una astilla en el dedo, que no se puede sacar, que nos hace llenar ese «aquí» de nuestras propias experiencias, intuyendo ese instante tan corto que casi parece una eternidad y que marca la distancia entre el solipsismo de cierta poesía y esta experiencia «comunal» que discurre sobre el lenguaje, sobre los cuerpos, sobre la dimensión humana que conmueve en la lectura.

\section{Bibliografía}

Estrada, Oswaldo: «Cristina Rivera Garza, en-clave de transgresión». In: Oswaldo Estrada (ed.): Cristina Rivera Garza. Ningún crítico cuenta esto. . ., p. 27-46. México: Eón 2010.

-: «Asignaciones de género y tareas de identidad en la narrativa de Cristina Rivera Garza». In: Oswaldo Estrada (ed.): Cristina Rivera Garza. Ningún crítico cuenta esto..., p. 179-200. México: Eón 2010.

Ferrús, Beatriz: «Sirenas, salvajes y mitologías de género en la narrativa de Cristina Rivera Garza». In: Helena Usandizaga y Beatriz Ferrús (eds.): Fragmentos de un nuevo pasado. Inventario de mitos prehispánicos en la literatura hispanoamericana actual, p. 105-117. Bern: Peter Lang 2015.

Kristeva, Julia: La révolution du langage poétique. Paris: Editions du Seuil 1981.

Palma Castro, Alejandro, Nathalie Galland Boudon, María Torres Ponce y Juan Rogelio Rosado Marrero: «La ficción más grande: la poesía de Cristina Rivera Garza». In: Alejandro Palma Castro et al. (coord.): Cristina Rivera Garza: una escritura impropia. Un estudio de su obra

67 Cristina Rivera Garza: «Saber demasiado». In: Oswaldo Estrada (ed.): Cristina Rivera Garza. Ningún crítico cuenta esto. . México: Eón 2010, p. 17-19.

68 Oswaldo Estrada: «Cristina Rivera», p. 27. 
literaria (1991-2014), p. 123-185. Puebla/México: Benemérita Universidad Autónoma de Puebla/Ediciones E y C 2015.

Quintana, Cécile: «El cuerpo-escritura de Cristina Rivera Garza». In: Graffylia 17-18 (2013), p. 130-142.

Rivera Garza, Cristina: Yo ya no vivo aquí. Los textos del yo. México: Fondo de Cultura Económica 2005.

-: «Saber demasiado». In: Oswaldo Estrada (ed.): Cristina Rivera Garza. Ningún crítico cuenta esto. .., p. 17-19. México: Eón 2010.

-: Escribir no es soledad. México: Universidad Autónoma de México, 2014.

Sánchez Prado, Ignacio M.: «El fin de la memoria: 〈Tercer Mundo〉 de Cristina Rivera Garza». In: Oswaldo Estrada (ed.): Cristina Rivera Garza. Ningún crítico cuenta esto. . ., p. 279-289. México: Eón 2010. 